\title{
On the Relation between the Concentration of the Nutrient Solution and the Rate of Growth of Plants in Water Culture.
}

BY

\section{WALTER STILES.}

INTRODUCTION.

F ROM time to time during the last fifty years various writers have pubI lished the results of their observations on the effect of the concentration of the nutrient solution on the growth of plants. As a result of these researches from those of Birner and Lucanus ${ }^{1}$ onwards, it has become clear that plants grow quite healthily in extremely dilute solutions, but it is not clear that the rate of growth of plants in such solutions is as great as that when higher concentrations are used. Recently Hall, Brenchley, and Underwood ${ }^{2}$ have attempted to show that concentration of the nutrient solution influences very greatly the rate of growth of plants. The observations of these writers agree so ill with the conclusions arrived at by other workers, notably by Cameron, ${ }^{3}$ that the publication of the results of some experiments on the effect of differences of concentration of the nutrient solution on growth seems justifiable.

\section{METHODS.}

In conducting experiments involving the use of water cultures two main difficulties present themselves. In the first place, plants growing in water cultures under exactly the same conditions are very variable. As evidence of this it is only necessary to cite the results of some work by Brenchley, ${ }^{4}$ where the dry weights of a number of plants growing in water culture under exactly similar conditions are given.

1 Birner und Lucanus: Wasserculturversuche mit Hafer. Landw. Versuchsstat., vol. viii, I866, pp. 128, I 77 .

2 Hall, A. D., Brenchley, W. E., and Underwood, L. M. : The Soil Solution and the Mineral Constituents of the Soil. Phil. Trans. B. 204, I913, pp. I79-200.

${ }^{3}$ Cameron, F. K. : The Soil Solution. Easton, Pa., I9I I.

4 Brenchley, W. E.: The Influence of Copper Sulphate and Manganese Sulphate upon the Growth of Barley. Annals of Botany, vol. xxiv, I9I0, pp. 57 I-83. 
The second difficulty arises from the phenomenon of selective absorption. All ions are not absorbed by the plant at the same rate; the result is that not only the concentrations but the relative proportion of the constituents of the nutrient solution is also changing.

In order to reduce the errors arising from these sources, seeds were used which were of as pure a strain as could be obtained, and which should therefore have yielded plants as alike as possible. The seeds were germinated in clean sand, and young seedlings as much alike as possible were selected.

The plants were grown singly in glass bottles of $\mathrm{I}, 200$ c.c. capacity and were done in sets of ten. The corks used were coated with paraffin, and the solutions were changed every few (five to three) days, except in some instances where inquiry was made into the effect of not changing the nutrient solution. All the cultures in any one series were started on the same day and were also harvested and dried at the same time, so that the results are strictly comparable.

Each plant was dried and weighed separately and the probable error of the mean of each set of ten results calculated, so that an idea of the significance of any differences in dry weight might be obtained.

The nutrient solutions used were of four different concentrations, but the proportions of the contained salts were the same in each. Ordinary 'pure' salts were used and a practically pure distilled water free from copper. The relative concentrations $\left(I, \frac{1}{5}, \frac{1}{10}, \frac{1}{20}\right)$ were the same as were used by Hall, Brenchley, and Underwood, but the actual proportion of salts was slightly different. The composition of the strongest solution was as follows :

$\begin{array}{lc}\mathrm{KNO}_{3} & 1 \quad \text { grm. } \\ \mathrm{CaSO}_{4},{ }_{2} \mathrm{H}_{2} \mathrm{O} & 0.25 ", \\ \mathrm{MgSO}_{4}, 7 \mathrm{H}_{2} \mathrm{O} & 0.25 \quad " \\ \mathrm{KH}_{2} \mathrm{PO}_{4} & 0.25 \quad " \\ \mathrm{NaCl} & 0.04 \quad " \\ \mathrm{Fe}\left(\mathrm{NO}_{3}\right)_{3}, 6 \mathrm{H}_{2} \mathrm{O} & 0.04 \quad " \\ \text { Water } & \text { I,000 c.c. }\end{array}$

\section{The Results.}

A preliminary series was grown during the early months of the year. The plant used was a Danish strain of Rye(Fejø,No.2), obtained for Professor Priestley by the kind offices of Professor Johannsen. Growth at this time of the year was slow, and consequently when the plants were removed they had not made very much growth. The actual results are as follows. The dry weight of each plant is given. 
Series I.

Cultures started February IO.

Solutions changed February I 3, I 7, 20, 24, 28, March 5, 7, I I.

Cultures harvested March 14.

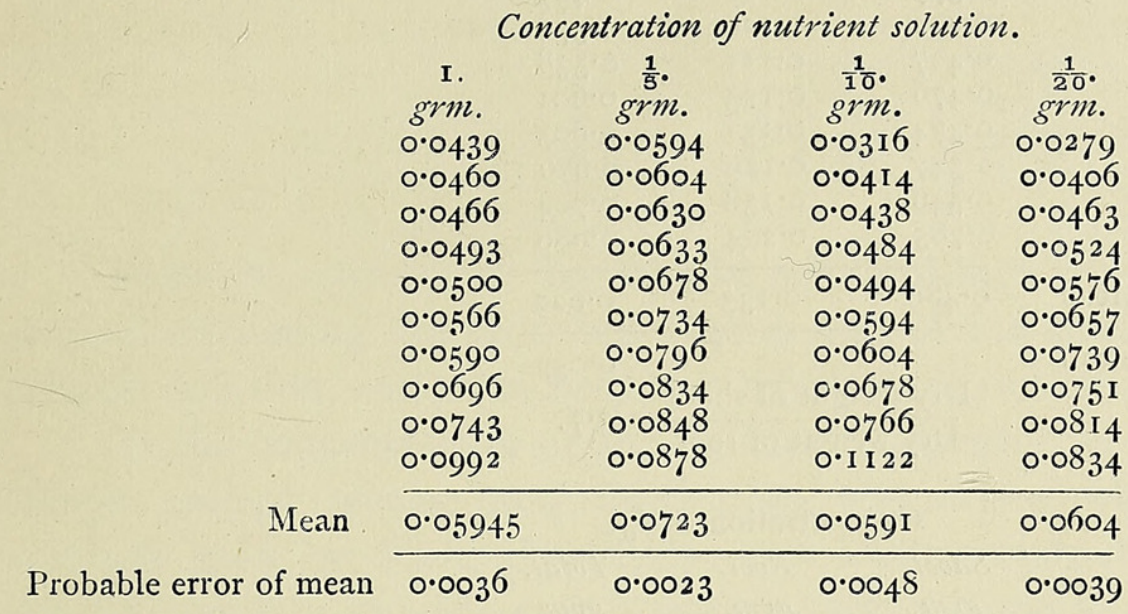

Reviewing these results after the probable error is taken into consideration, it will be observed that there is not much appreciable difference between the mean dry weights of the plants growing in solutions of different concentration.

A series was grown during the spring in which Barley was employed as the culture plant. Seed of a pure line was used which was kindly sent by Professor Biffen to Professor Priestley. The growth of these plants was much more rapid than that of the Rye grown earlier in the year. The weights of the shoot and root of each plant were taken separately. The results of this series are as follows:

Series 2.

Cultures started April 28.

Solutions changed May 5, 8, I3, I 8, 22, 26, 29, June 2.

Cultures harvested June 6 .

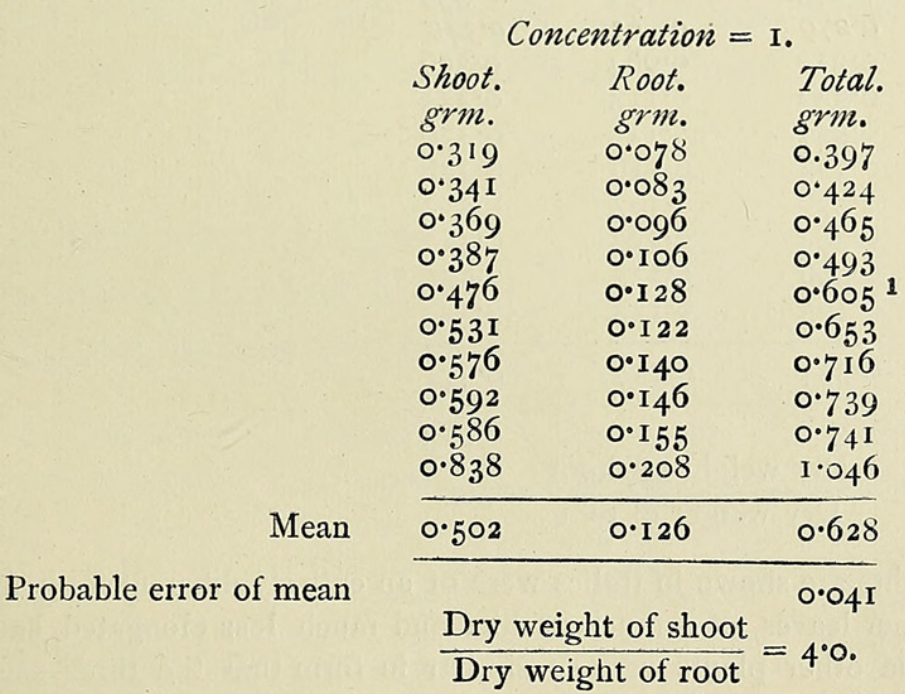

${ }^{1}$ In all cases the plants were weighed to a tenth of a milligram, but the numbers are here given correct to the third decimal place. 


\begin{tabular}{|c|c|c|c|}
\hline & & ntration $=$ & $\frac{1}{5}$. \\
\hline & Shoot. & Root. & Total. \\
\hline & $\begin{array}{c}\text { grm. } \\
o \cdot 239\end{array}$ & $\begin{array}{l}\text { grm. } \\
0.082\end{array}$ & $\begin{array}{l}g r m . \\
o^{*} 320^{1}\end{array}$ \\
\hline & 0.359 & 0.097 & $0 \cdot 45^{6}$ \\
\hline & 0.377 & 0.120 & 0.497 \\
\hline & 0.412 & 0.120 & $0.53^{2}$ \\
\hline & 0.427 & O.III & $0.53^{8}$ \\
\hline & 0.476 & 0.125 & 0.601 \\
\hline & 0.474 & $0.13 I$ & 0.605 \\
\hline & 0.547 & 0.129 & 0.676 \\
\hline & 0.546 & $0 \cdot 15^{8}$ & 0.704 \\
\hline & $0.7^{8} 5$ & 0.204 & 0.989 \\
\hline Mean & 0.489 & $0 \cdot 133$ & 0.622 \\
\hline Probable error of mean & & & 0.035 \\
\hline & $\frac{\text { Dry v }}{\text { Dry }}$ & ht of root & $=3.7$ \\
\hline & & tration $=$ & \\
\hline & Shoot. & Root. & Total. \\
\hline & $\begin{array}{l}g r m \\
o \cdot 188\end{array}$ & $\begin{array}{l}\text { grm. } \\
o \cdot 080\end{array}$ & $\begin{array}{c}g r m . \\
o \cdot 268\end{array}$ \\
\hline & 0.315 & 0.080 & $0 \cdot 395$ \\
\hline & 0.313 & 0.099 & 0.412 \\
\hline & 0.382 & $0 \cdot 10 \mathrm{I}$ & 0.483 \\
\hline & $0 \cdot 361$ & $0 \cdot 136$ & 0.497 \\
\hline & 0.425 & O.II 2 & 0.537 \\
\hline & $0.4 \mathrm{I} 5$ & 0.140. & 0.554 \\
\hline & 0.466 & 0.124 & 0.590 \\
\hline & 0.569 & O.I $5 \mathrm{I}$ & 0.721 \\
\hline & 0.6 I I & $0 \cdot 19^{8}$ & $0 \cdot 809$ \\
\hline Mean & 0.429 & 0.127 & 0.555 \\
\hline Probable error of mean & & & 0.030 \\
\hline & Dry & ht of shoo & $=3 \cdot 4$. \\
\hline & Dry & hit of root & $544^{\circ}$ \\
\hline & & atration $=$ & \\
\hline & Shoot. & Root. & Total. \\
\hline . & $\begin{array}{l}g r m . \\
0.243\end{array}$ & $\begin{array}{l}\text { grm. } \\
0.096\end{array}$ & $\begin{array}{l}\mathrm{grm} . \\
0 \cdot 339\end{array}$ \\
\hline & 0.279 & 0.063 & 0.342 \\
\hline & 0.312 & 0.084 & $0 \cdot 396$ \\
\hline & 0.342 & O.II 3 & 0.455 \\
\hline & 0.357 & O.II 3 & 0.470 \\
\hline & 0.362 & $0 \cdot 116$ & 0.478 \\
\hline & 0.370 & $0 \cdot 143$ & $0.5 \mathrm{I} 3$ \\
\hline & 0.394 & 0.123 & 0.517 \\
\hline & 0.396 & 0.135 & $0.53 \mathrm{I}$ \\
\hline & 0.405 & $0 \cdot 133$ & 0.538 \\
\hline Mean & 0.354 & 0.117 & 0.471 \\
\hline Probable error of mean & $\frac{\text { Dry }}{\text { Dry }}$ & ht of shoo & $\begin{aligned} & 0.015 \\
= & 3.0 .\end{aligned}$ \\
\hline
\end{tabular}

1 The plants whose dry weights are shown in italics were of an entirely different form from the rest. They were smaller, with finer leaves, of a much bushier and much less elongated habit, and of a much darker green. All the other plants were so similar in form that the three exceptions noted in the tables are obviously not in the pure line. Their dry weights have therefore not been considered in calculating the mean or the probable error. 
Summarizing these results and taking the probable error into account the following numbers are obtained:

\begin{tabular}{ccc} 
Concentration of & $\begin{array}{c}\text { Dry weight in grm. } \\
\text { Highest and lowest }\end{array}$ \\
mutrient solution. & \multicolumn{2}{c}{ numbers. } \\
I & 0.669 & 0.587 \\
$\frac{1}{3}$ & 0.657 & 0.587 \\
$\frac{1}{10}$ & 0.585 & 0.525 \\
$\frac{1}{20}$ & 0.486 & $0.45^{6}$
\end{tabular}

Thus the only mean dry weight which differs from the others by an amount exceeding the probable error is that of the cultures growing in the dilutest solution, and even here the difference is not very great.

As the concentration of this particular solution is less in all essential things, except nitrate and iron, than the lowest strength of nutrient solution used by Hall, Brenchley, and Underwood, it is surprising that the difference in the dry weight between the cultures grown in this solution and those grown in the highest strengths should be so small. The numbers obtained by Hall, Brenchley, and Underwood are as follows :

$\begin{array}{cc}\text { Concentration of } & \text { Dry weight. } \\ \text { mutrient solution. } & 0.420 \\ \text { I } & 0.244 \\ \frac{1}{5} & 0.108 \\ \frac{1}{10} & 0.068 \\ \frac{1}{20} & \end{array}$

In order to determine whether an infrequent changing of the nutrient solutions influences the result, two further series of Barley cultures were grown in solutions which were seldom changed. In all other respects these cultures were conducted similarly to the others. They were done in sets of ten and the probable error of the mean dry weight of each set calculated. The numbers already given serve to illustrate the variation in dry weight obtained within one set, and so individual results are not given in the following tables. The results are as follows :

\section{Series 3 .}

Cultures started April 30.

Solutions changed May i I, 2I.

Cultures harvested June 9.

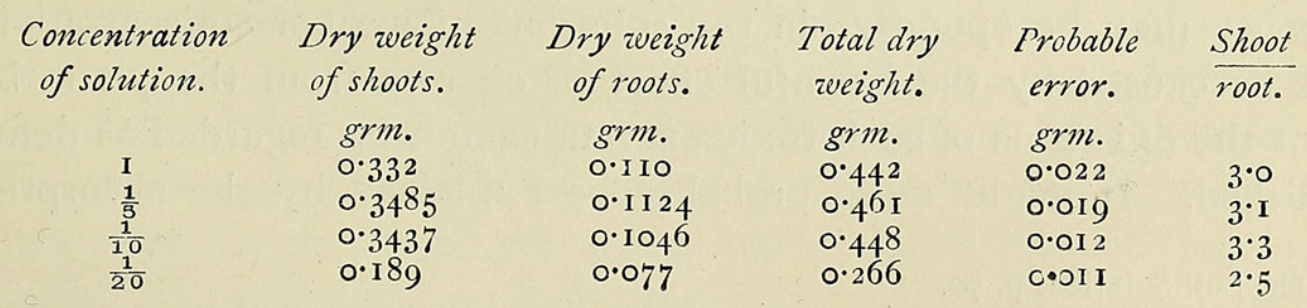




\section{Series 4 .}

Cultures started May I.

Solutions changed May 25.

Cultures harvested June $\mathbf{I} 2$.

$\begin{array}{cccccc}\begin{array}{c}\text { Concentration } \\ \text { of solution. }\end{array} & \begin{array}{c}\text { Dry weight } \\ \text { of shoots. }\end{array} & \begin{array}{c}\text { Dry weight } \\ \text { of roots. }\end{array} & \begin{array}{c}\text { Total dry } \\ \text { weight. }\end{array} & \begin{array}{c}\text { Probable } \\ \text { error. }\end{array} & \frac{\text { Shoot }}{\text { root. }} \\ & \text { grm. } & g r m . & g r m . & g r m . & \\ \text { I } & 0.227 & 0.085 & 0.312 & 0.017 & 2.7 \\ \frac{1}{5} & 0.325 & 0.103 & 0.428 & 0.02 \mathrm{I} & 3.2 \\ \frac{1}{10} & 0.377 & 0.123 & 0.500 & 0.020 & 3 . \mathrm{I} \\ \frac{1}{20} & 0.2826 & 0.1287 & 0.4 \mathrm{II} & 0.018 & 2.2\end{array}$

\section{DisCUSSION OF RESULTS.}

The results recorded in the preceding section of this paper indicate that if the nutrient solutions in water-culture experiments are changed frequently, so as to maintain more nearly a constant composition of the solution, the concentration of the solution may vary considerably without producing much effect on the rate of growth of the cultures as measured by the dry matter produced within a given time. Below a certain concentration, however, there seems to be an indication that the rate of growth becomes less, although this falling off is not very marked in the lowest concentration employed in these experiments, and not nearly so marked as the falling off in the growth recorded by Hall, Brenchley, and Underwood for the same species growing in rather similar concentration. Indeed, the results concerning Rye and Barley recorded in the present paper are exactly described by Cameron when he states with regard to water-culture experiments with Wheat, "that if a given ratio of mineral nutrients be maintained, relatively small effect is produced on the growing plants by varying the concentration over a wide range'. ${ }^{1}$ The recently published work of Tottingham ${ }^{2}$ indicates the same conclusion. It should be stated that the plants which had produced the least dry matter were quite healthy plants and showed no sign of weakening.

Indeed, of the 160 plants grown none died nor showed any sign of lack of vigour when the cultures were stopped.

It will be observed that when the nutrient solutions remain unchanged a marked depression of the rate of growth occurs. This can scarcely be due to lack of salt in the strongest nutrient solutions, although this cause may be operative in the solutions of weaker concentration. It might be caused by the harmful effect of excreta from the plant, but at present the existence of such toxic excreta cannot be regarded as definitely established. It might more probably be explained by the absorption of

1 The Soil Solution, p. 7o.

2 Tottingham, W. E. : A Quantitative Chemical and Physiological Study of Nutrient Solutions for Plant Cultures. Physiol. Researches, vol. i, I9I 4, Pp. I33-245. 
different ions at different rates which would result after a time in an alteration of the relative proportions of the different substances in the solution. The necessity for a definite balance between the substances in a nutrient solution has been emphasized by many workers recently. The effect of this selective absorption would be extremely difficult to foretell, as it would probably produce different results in solutions of different concentrations. In the strongest solutions, however, the toxic properties of the substance in excess would probably be most marked, while in the weakest solution a starvation effect owing to exhaustion of some particular salt or ion might result. In any case it would appear to be essential in many water-culture experiments to renew the culture solutions at frequent intervals, and possibly to use culture jars or bottles of large capacity.

One point which may be worth mentioning is that of the ratio of the dry weight of the shoot to that of the root. It would appear that with decreasing concentration of the solution the growth of the shoot is affected much more than that of the root, a fact which is also indicated by Hall, Brenchley, and Underwood's figures. ${ }^{1}$ When the culture-solutions are not changed frequently, the growth of the shoots is again affected more than that of the roots.

It seems necessary to lay emphasis on the extreme variability of plants growing in water-cultures, particularly as regards their dry weight. The numbers given by Brenchley, already referred to in this paper, and some given by Hall, Brenchley, and Underwood, ${ }^{2}$ make it quite clear that in order to obtain definite results by the water-culture method it is essential to use a fairly large number of plants, and to weigh the dry matter of each plant separately and calculate the probable error.

Only by this means can an indication be obtained as to whether any difference is significant. By reference to the figures in this paper it will be seen that working with sets of ten plants under the same conditions does not allow of the measurement of moderately small differences even when a pure line of seed is used. Hall, Brenchley, and Underwood's cultures were only grown in duplicate, and this may account for the differences between their results and those of other observers.

What bearing the results of experiments with water-cultures can have on the question of the soil solution it is difficult, and would indeed be premature, to say. To argue from a comparatively simple medium, such as a nutrient solution of mineral salts, to a complex structure like the soil, is indeed a risky thing to do in the present state of our knowledge. It seems, however, safe to say that the present experiments, like those of most other observers, support Cameron's contention that the soil solution, dilute as he supposes it to be, is yet quite concentrated enough to support vegetation. In this connexion it is interesting to compare the quantities of

\footnotetext{
1 Hall, Brenchley, and Underwood: 1. c., pp. I9I, I93.
}

${ }^{2}$ 1. c., pp. I9I, I95. 
potassium and phosphate in the various solutions used in these experiments with the quantities found by Cameron to be present in the soil solution.

\begin{tabular}{cccccc} 
Parts per & \multicolumn{4}{c}{ Concentration of solution. } & Soil solution \\
I0 & according to \\
$\mathrm{I}^{6}$ of & $\mathrm{I}$ & $\frac{1}{5}$ & $\frac{1}{10}$ & $\frac{1}{20}$ & Cameron. \\
$\mathrm{K}_{2} \mathrm{O}$ & $\mathbf{5 5 2}$ & $\mathrm{I} 10$ & 55 & 28 & about 28 \\
$\mathrm{P}_{2} \mathrm{O}_{5}$ & $\mathrm{I}_{3} \mathrm{I}$ & 26 & $\mathbf{1} 3$ & $6 \cdot 5$ & about 7
\end{tabular}

Thus the weakest solution when first put in the culture jars was of the same strength in regard to potash and phosphate as that of the soil solution. This probably means that its average strength during the time it was in the culture bottles was somewhat less; and although the plants grown in this dilutest solution produced somewhat less dry matter than those in higher strengths, the difference was not great and the plants were perfectly healthy.

Finally, it should be pointed out that such results as those here recorded cannot be regarded as in any way general. Although all the plants in one series were grown under apparently exactly the same conditions, yet it is possible that under a different set of conditions a different result might be obtained. Again, different species might show different effects in regard to concentration of the nutrient solution. It must be left for future work to deal with these questions.

\section{SUMMARY.}

I. The variation over a fairly wide range of the concentration of the nutrient solution of Rye and Barley growing in water culture produces relatively little effect on the amount of dry matter produced. Below a certain concentration there appears to be a definite falling off in the rate of growth.

2. The concentration of the soil solution as estimated by Cameron, low as it is, is yet high enough to produce healthy plants.

3. Frequent changing of the nutrient solution of water cultures produces decidedly better growth of the plants.

4. It is necessary to calculate the probable error of the results obtained in experiments with water-cultures in order to determine the significance of differences between results from different sets of cultures.

Botany Department,

The University, Leeds.

Fune $25,19 \mathrm{I} 4$. 


\section{$2 \mathrm{BHL}$ Biodiversity Heritage Library}

Stiles, Walter. 1915. "On the relation between the concentration of the nutrient solution and the rate of growth of plants in water culture." Annals of botany 29, 89-96. https://doi.org/10.1093/oxfordjournals.aob.a089539.

View This Item Online: https://www.biodiversitylibrary.org/item/243629

DOI: https://doi.org/10.1093/oxfordjournals.aob.a089539

Permalink: https://www.biodiversitylibrary.org/partpdf/320052

\section{Holding Institution}

Smithsonian Libraries

\section{Sponsored by}

Biodiversity Heritage Library

\section{Copyright \& Reuse}

Copyright Status: Not in copyright. The BHL knows of no copyright restrictions on this item.

This document was created from content at the Biodiversity Heritage Library, the world's largest open access digital library for biodiversity literature and archives. Visit BHL at https://www.biodiversitylibrary.org. 